\title{
Reviewers - the backbone of academic publishing
}

As we end 2016 - which has effectively been my first year as de facto editor of the SAMJ - I have a bit of time to reflect. It has been a steep learning curve - going from working with a highly respected academic who made most of the decisions, to taking over - with all the slings and arrows that come with this! On a run recently I chatted briefly to my old teacher and friend, Raymond Abratt, who said that he was warned, as editor of a journal, that he wouldn't have many friends left! As a professional editor, rather than an academic, I may have been somewhat immune to this, and I have certainly enjoyed my expanded role.

However, what has not always been easy is trying to find reviewers for all the papers submitted to us. In this issue we thank all those who have reviewed for us during the course of 2016, and it looks like a long list. However, there are times when it proves almost impossible to find reviewers for some articles, which leaves us in a very difficult position. We offer a service to researchers in South African medicine - publishing the papers that report their research. To comply with the highest of international standards, we need all these papers, with very few exceptions, to be reviewed. Reviewers are the backbone of academic publishing. Without you, we cannot publish.

I know that academics in medical disciplines in South Africa are under increasing pressure. The demands of medical practice, teaching, research and, increasingly, politics are enormous, so requests to review papers mean yet another burden on your time. But I would make the plea, as we end this very difficult academic year, to please find the time. If we have more reviewers, there will be fewer requests to those who routinely review for us. In turn, we are making an effort to ensure that the papers we do send for review comply with our author guidelines - not always easy, and probably the topic of another editorial comment in the new year!

I will finish 2016 with much thanks and appreciation to all who have supported my team and me during the past year, and also end with a plea to everyone to try, whenever possible, to respond positively to our requests for review when they land in your inbox.

\section{Bridget Farham \\ Editor \\ ugqirha@iafrica.com}

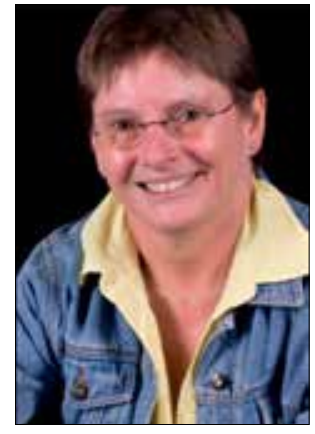

S Afr Med J 2016;106(12):1149. DOI:10.7196/SAMJ.2016.v106i12.12186 